\title{
AVALIAÇÃO DA CONTAMINAÇÃO DE CORPOS D'ÁGUA ADJACENTES A ÁREAS AGRÍCOLAS DA ILHA DE SÃO LUÍS (MA) POR AGROTÓXICOS
}

\author{
CLARENICE LOIOLA DOS SANTOS* \\ HAMANDA S.V.P. DA SILVA* \\ GILDA VASCONCELLOS DE ANDRADE ** \\ GILVANDA SILVA NUNES ***
}

\begin{abstract}
Efetuou-se levantamento sobre os principais agrotóxicos utilizados por agricultores da zona rural da llha de São Luís (MA), visando analisar os níveis de contaminação de corpos d'água adjacentes aos pólos agrícolas locais. Segundo os critérios avaliados neste estudo, os agrotóxicos investigados apresentam riscos de contaminação do ambiente, dos agricultores e da população em geral. Em algumas das amostras de água foi detectada inclusive a presença de agrotóxico organoclorado, cujo uso agrícola no Brasil foi proibido há mais de duas décadas.
\end{abstract}

* Mestres em Biodiversidade e Conservação pela Universidade Federal do Maranhão (UFMA), São Luis, MA (e-mail: claraloiola@gmail.com; hamandasoares@gmail.com).

** Professora (Co-orientadora), Departamento de Biologia, UFMA, São Luís, MA (e-mail: gildavandrade@ gmail.com).

*** Professora (Orientadora), Departamento de Tecnologia Química, UFMA, São Luís, MA (e-mail: gilvanda@ pq.cnpq.br). 


\section{INTRODUÇÃO}

O uso de agrotóxicos, prática comum para o combate de diversas pragas, tem como objetivo aumentar a produção e melhorar a qualidade dos produtos. Pode-se ressaltar que grande parte desses objetivos foi alcançada ao longo dos anos, porém a utilização pouco criteriosa desses compostos vem causando a contaminação de organismos alvos e não alvos e, consequentemente, do meio ambiente (COUTINHO, 2005).

Os agrotóxicos, quando em contato com o solo, a água e o ar podem persistir nesses compartimentos ambientais e também se acumularem no solo e na biota. Os seus resíduos podem ser carreados para as águas superficiais por escoamento e para as águas subterrâneas por lixiviação (DORES e FREIRE, 2001). Há diversas rotas que esses agroquímicos podem percorrer e variadas são as suas formas de transformação e degradação no ambiente. Contudo, sabe-se que a contaminação das águas afeta os anfíbios (PELTZER et al. 2006), peixes (FAVERO, SOUZA e MATIAS, 2005), crustáceos, moluscos e insetos (LEONARD, 1990). Assim, essas substâncias podem intoxicar diversos organismos e causar danos à saúde humana através da ingestão de água e alimentos contaminados (DOMINGUES et al. 2004).

A agricultura Maranhense constitui a principal atividade econômica do Estado e a zona rural da llha de São Luís conta com mais de 22 pólos de produção agrícola (ARAÚJO, 2001). Assim, verifica-se a necessidade de investigar os impactos que os agrotóxicos podem causar ao meio ambiente e para a saúde dos produtores e da população em geral.

O presente estudo teve como objetivo realizar análises de resíduos de agrotóxicos nos corpos d'água adjacentes a áreas agrícolas da llha de São Luís, empregando métodos cromatográficos e imunoquímicos (ELISA), além de obter informações no campo sobre os principais produtos utilizados por agricultores da região e suas condições de trabalho.

\section{MATERIAL E MÉTODOS}

\subsection{DESCRIÇÃO DA REGIÃO DO ESTUDO}

A zona metropolitana de São Luís está dividida em quatro municípios: São Luís, São José de Ribamar, Raposa e Paço do Lumiar. As coletas de campo para análise de resíduo de agrotóxico ocorreram em áreas agrícolas, localizadas na zona rural da ilha de São Luís (MA). No sistema de agricultura familiar predominante nessa região, os agricultores trabalham principalmente por meio da preparação manual do solo, normalmente em área de 1 ha por família, iniciando o processo de produção a partir de mudas (SOUZA, 2009).

\subsection{LEVANTAMENTO DOS AGROTÓXICOS UTILIZADOS NAS ÁREAS AGRÍCOLAS DA ILHA DE SÃO LUÍS}

Aseleção de agrotóxicos para este estudo foi realizada por meio da aplicação de questionários junto aos produtores da região, visando levantar dados sobre: produtos aplicados para o controle de pragas; dosagens usadas; período de carência (intervalo em dias que decorrem da última aplicação do agrotóxico à colheita); destino das embalagens (local usado pelos produtores para descartar as embalagens vazias) e utilização de equipamentos de segurança e de proteção individual (EPI). As entrevistas foram efetuadas em cinco pólos de produção, localizados nos municípios de São Luís (2 pólos), Paço do Lumiar, Raposa e São José de Ribamar (Tabela 1). A escolha desses pólos ocorreu em função da prevalência de produção de hortaliças e legumes, na llha do Maranhão. Foram entrevistados 82 trabalhadores rurais. Na maioria das vezes, as entrevistas ocorreram nas residências dos trabalhadores, situadas próximas às áreas de plantio. Em alguns casos, como na localidade Talita, os dados foram obtidos no próprio local de plantio. 
TABELA 1 - DESCRIÇÃO DOS PÓLOS DE PRODUÇÃO AGRÍCOLAS ESTUDADOS E SEUS PONTOS DE COLETA

\begin{tabular}{lll}
\hline MUNICíPIO & LOCALIDADE & $\begin{array}{l}\text { COORDENADA } \\
\text { GEOGRÁFICA }\end{array}$ \\
\hline São Luís & Cinturão Verde & $02^{\circ} 38^{\prime} S 44^{\circ} 13^{\prime} \mathrm{O}$ \\
São José de Ribamar & São Braz dos Macacos & $02^{\circ} 35^{\prime} \mathrm{S} 44^{\circ} 09^{\prime} \mathrm{O}$ \\
Paço do Lumiar & Iguaíba & $02^{\circ} 30^{\prime} \mathrm{S} 44^{\circ} 06^{\prime} \mathrm{O}$ \\
Raposa & Talita & $02^{\circ} 28^{\prime} \mathrm{S} 44^{\circ} 09^{\prime} \mathrm{O}$ \\
& Açude Talita & $02^{\circ} 27^{\prime} \mathrm{S} 44^{\circ} 08^{\prime} \mathrm{O}$ \\
\hline
\end{tabular}

\subsection{COLETAS DAS AMOSTRAS DE ÁGUAS E SEDIMENTO DOS PÓLOS AGRÍCOLAS E PRÉ-TRATAMENTO}

Dos cinco pólos de produção, dois mais representativos foram escolhidos para a realização das análises de resíduos de agrotóxicos em amostras de água e sedimento. As coletas ocorreram no dia 25 de abril de 2010, nas áreas agrícolas de Talita (Raposa), Açude Talita (Raposa) e São Braz dos Macacos (São José de Ribamar) (Figura 1).

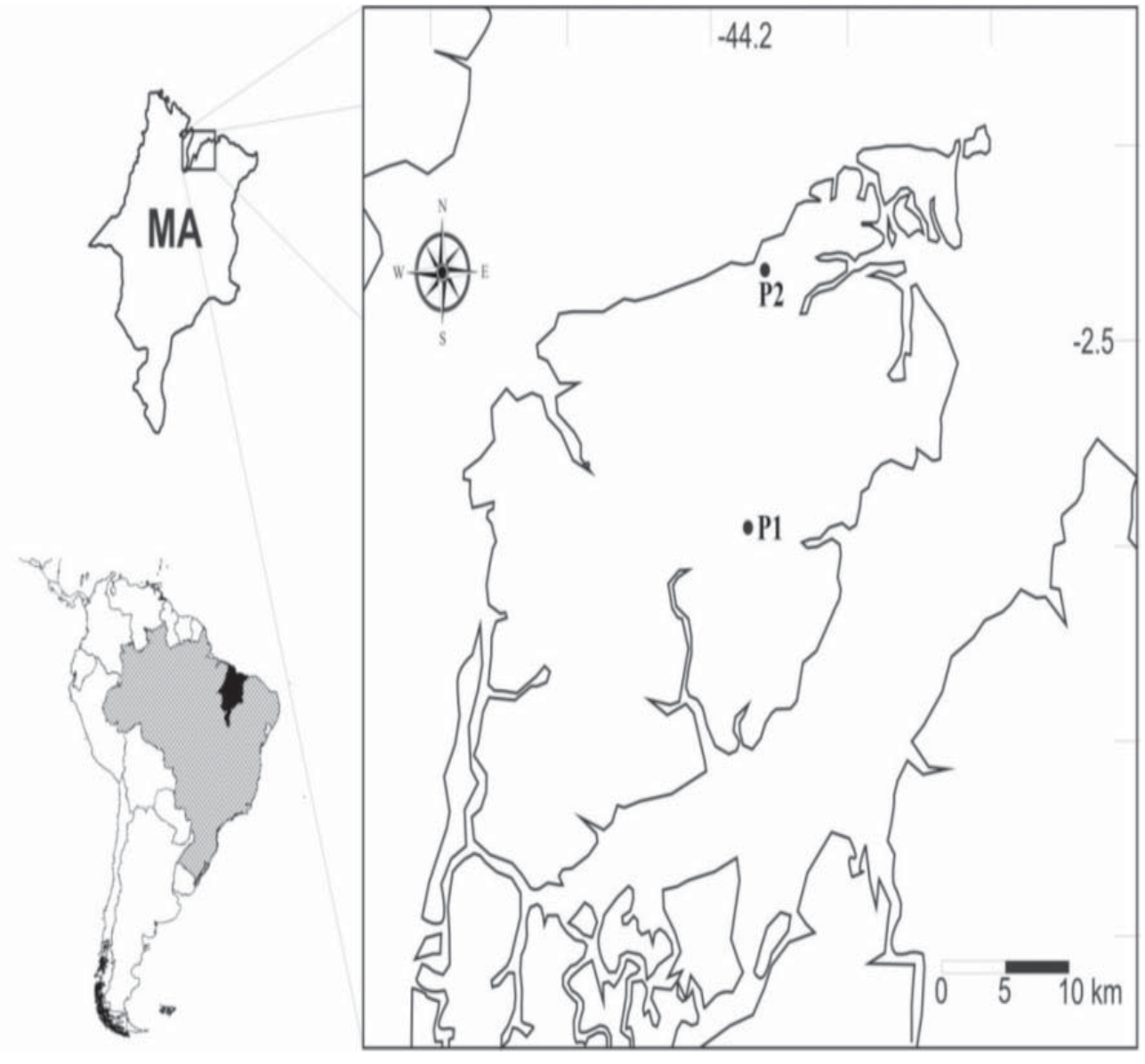

\section{FIGURA 1 - PÓLOS AGRÍCOLAS DA ILHA DE SÃO LUÍS NOS QUAIS FORAM COLETADAS AMOSTRAS DE ÁGUA PARA A DETECÇÃO DE CONTAMINANTES}

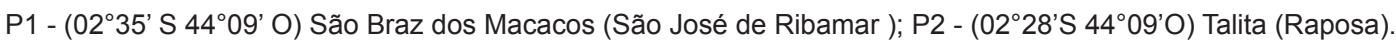


Para a coleta das amostras de água foram utilizados frascos âmbar de $1 \mathrm{~L}$ de capacidade. As amostras foram transportadas em caixa de isopor com gelo e mantidas resfriadas $\left(-4^{\circ} \mathrm{C}\right)$ até 0 término das preparações iniciais, no Laboratório do Núcleo de Análises de Resíduos de Pesticidas da Universidade Federal do Maranhão (NARP/UFMA). Para o transporte do sedimento foram utilizados potes plásticos, devidamente lacrados e identificados. As coletas das amostras de águas e sedimentos seguiram os protocolos descritos pela Agência Americana de Proteção Ambiental (USEPA, 2007) com pequena modificação: as amostras de água destinadas aos testes imunoquímicos não foram preservadas em ácido para que não ocorresse alteração nos resultados, devido diminuição drástica do pH. Tais amostras foram tratadas no máximo 24 horas após a coleta, a fim de evitar a degradação dos princípios ativos presentes (NUNES, 2005). As amostras destinadas às análises cromatográficas foram preservadas gotejando-se, logo após a coleta, ácido sulfúrico concentrado até se obter valor de $\mathrm{pH}<2,0$ (US-EPA, 2007).

\subsubsection{Filtração das amostras de água}

Realizou-se filtração a vácuo das amostras, primeiro com filtro qualitativo e depois utilizando membranas filtrantes (poros de 0,45 $\mu \mathrm{m}$ de diâmetro, da Merck $^{\circledR}$ ) até retirar o máximo de matéria orgânica e sedimentos. Para a filtração com membranas empregou-se o sistema Millipore ${ }^{\circledR}$ (Merck) (US-EPA, 2007).

\subsubsection{Extração em Fase Sólida (EFS)}

Os métodos usados na análise de resíduos de agrotóxicos em água exigem a extração e a pré-concentração desses compostos. Entre as técnicas mais utilizadas destaca-se a extração em fase sólida (EFS), que permite diminuir o tempo da análise e o consumo de solventes. São, tradicionalmente, empregados cartuchos contendo adsorventes específicos para retenção dos princípios ativos de interesse, com a vantagem de se poder armazená-los em geladeira ou em freezer, após uso, para eluição dos compostos e análises futuras (SANTOS NETO e SIQUEIRA, 2005).

Foram utilizados cartuchos de marca SampliQ $C_{18}(5 \times 6 \mathrm{~mL}, 500 \mathrm{mg})$ e o sistema Manifold para o procedimento EFS. Os cartuchos foram previamente acondicionados, passando-se $10 \mathrm{~mL}$ de metanol e depois $10 \mathrm{~mL}$ de água deionizada em cada um, com fluxo de 2 a $3 \mathrm{~mL} / \mathrm{min}$. Após o acondicionamento, foram adicionados $500 \mathrm{~mL}$ de amostra. Com o término da passagem da amostra, o cartucho foi seco sob vácuo por aproximadamente $1 \mathrm{~h}$. Os compostos ficaram fixados na fase adsorvente do cartucho, os quais foram armazenados em geladeira para posterior análise dos princípios ativos.

\subsubsection{Retomada dos resíduos e análises químicas e imunoquímicas dos agrotóxicos}

Após a etapa de extração/pré-concentração, os cartuchos secos foram enviados ao Laborátorio BIOMEM da Universidade de Perpignan Via Domitia (UPVD), Perpignan (França). Os agrotóxicos foram eluídos, em cada cartucho, com $5 \mathrm{~mL}$ da mistura metanol-acetonitrila (1:1) e o eluato recolhido em balão de fundo redondo para posterior rota-evaporação à temperatura de $35^{\circ} \mathrm{C}$. Quando necessário, passou-se corrente suave de $\mathrm{N}_{2}$ para completar a etapa de secagem. Os resíduos dos produtos foram então reconstituídos em $1 \mathrm{~mL}$ de acetonitrila grau HPLC (Merck ${ }^{\circledR}$ ). Desse modo, o fator de pré-concentração foi de 500 vezes, o que possibilitou atingir os limites de detecção da maioria dos agrotóxicos investigados.

A presença dos agrotóxicos nos extratos finais foi detectada, inicialmente pelo método Elisa. Nesse caso, realizou-se diluição (fator 1:10) do extrato final com tampão fosfato $\mathrm{pH} 7,5$, antes da execução do ensaio imunoquímico. A Tabela 2 lista os tipos de imunoensaios utilizados nessa etapa do trabalho, bem como a sensibilidade de cada teste. 


\section{TABELA 2 - INFORMAÇÕES SOBRE OS KITS DE ELISA UTILIZADOS NA DETECÇÃO PRELIMINAR DOS AGROTÓXICOS}

\begin{tabular}{|c|c|c|c|c|}
\hline $\begin{array}{l}\text { Identificação } \\
\text { do kit* }\end{array}$ & $\begin{array}{l}\text { Agrotóxicos ou grupo de } \\
\text { agrotóxicos analisados }\end{array}$ & $\begin{array}{c}\text { Tipo de } \\
\text { imunoensaio }\end{array}$ & $\begin{array}{l}\text { Faixa de } \\
\text { trabalho } \\
\left(\mu g \cdot L^{-1}\right)\end{array}$ & $\begin{array}{c}\text { Limite de } \\
\text { detecção }\left(\mu \mathrm{g} \cdot \mathrm{L}^{-1}\right)\end{array}$ \\
\hline EP-014 & $\begin{array}{l}\text { Inseticidas inibidores da enzima } \\
\text { acetilcolinesterase (carbamatos e } \\
\text { organofosforados) }\end{array}$ & $\begin{array}{l}\text { ELISA (kit contendo } \\
\text { placas com micro- }\end{array}$ & $0,2-50$ & 0,1 \\
\hline EP-021 & $\begin{array}{c}\text { Inseticidas organoclorados (não } \\
\text { sistêmicos, como ciclodienos e } \\
\text { DDT) }\end{array}$ & orifícios) & $10-20$ & 6 \\
\hline EP-012 & Piretroides sintéticos & $\begin{array}{l}\text { ELISA (kit contendo } \\
\text { placas com } \\
\text { micro-orifícios } \\
\text { cobertos com } \\
\text { anticorpos) }\end{array}$ & - & 0,5 \\
\hline EP-003 & $\begin{array}{c}\text { Triazinas (herbicidas sistêmicos } \\
\text { seletivos) }\end{array}$ & & $0,04-4$ & 0,01 \\
\hline EP-002 & $\begin{array}{l}\text { Aldicarb (inseticida sistêmico, } \\
\text { acaricida e nematicida) }\end{array}$ & & $3-100$ & 2,6 \\
\hline EP-004 & $\begin{array}{c}\text { Clorpirifós (inseticida } \\
\text { organofosforado, não sistêmico) }\end{array}$ & & $0,3-6,0$ & 0,3 \\
\hline
\end{tabular}

* Testes adquiridos diretamente da empresa EnviroLogix ${ }^{\circledR}$ (Portland, Maine, EUA).

Detectados os grupos de agrotóxicos presentes em cada amostra, a confirmação ocorreu mediante cromatografia a gás, empregando-se detector por captura de elétrons (GC/ECD) ou por espectrometria de massas (GC/MS). A presença dos agrotóxicos nos extratos finais foi detectada, inicialmente, pelo método ELISA. Nesse caso, realizou-se diluição (fator 1:10) do extrato final com tampão fosfato $\mathrm{pH} 10$, antes da aplicação do ensaio imunoquímico. Para a determinação e confirmação dos resíduos de inseticidas organofosforados (OF) empregou-se o método analítico descrito por Santos Neto e Siqueira (2005). Para as análises dos inseticidas piretroides (PR) e organoclorados $(\mathrm{OC})$ usou-se o método multirresidual semiautomático, baseado no acoplamento da técnica de microextração (MEFS) em fase sólida e determinação por CG/MS (CALDAS et al., 2011) com adaptações. O método foi previamente validado no Laboratório BIOMEN/UPVD, conforme as recomendações da Conferência Internacional em Harmonização (ICH, 1996).

\section{RESULTADOS E DISCUSSÃO}

\subsection{PRINCIPAIS AGROTÓXICOS UTILIZADOS NOS PÓLOS DE PRODUÇÃO DA ILHA DE SÃO LUÍS NO ANO DE 2010}

No levantamento, realizado presencialmente nos pólos de produção, verificou-se o uso predominante dos inseticidas organofosforados (OP), seguidos pelos piretroides (Tabela 3).

Entre os inseticidas OF mais utilizados no período estudado encontra-se o metamidófos ${ }^{\circledR}$, classificado pelo CONAMA como altamente tóxico para mamíferos e organismos aquáticos, além de muito perigoso ao ambiente (FAVERO, SOUZA e MATIAS, 2005). Em seguida, tem-se o inseticida paration metílico classificado como extremamente tóxico e muito danoso ao ambiente, tanto que se recomenda sua aplicação a 500 metros de distância de mananciais, moradias isoladas, agrupamento de animais e vegetação suscetível a danos (PERES e MOREIRA, 2008). 
TABELA 3 - PRINCIPAIS PRODUTOS COMERCIAIS (AGROTÓXICOS) UTILIZADOS NAS ÁREAS INVESTIGADAS, SEUS PRINCÍPIOS ATIVOS E INFORMAÇÃO TOXICOLÓGICA

\begin{tabular}{|c|c|c|c|c|c|}
\hline $\begin{array}{c}\text { Nome } \\
\text { comercial }\end{array}$ & Classe & $\begin{array}{c}\text { Classe } \\
\text { toxico- } \\
\text { lógica }\end{array}$ & $\begin{array}{l}\text { Ingrediente } \\
\text { ativo }\end{array}$ & Grupo químico & $\begin{array}{l}\text { Pólos de } \\
\text { produção }\end{array}$ \\
\hline Decis & Inseticida & III & Deltametrina & Piretroide & Cinturão Verde \\
\hline $\begin{array}{c}\text { Folisuper } \\
600 \text { BR }\end{array}$ & Inseticida & 1 & $\begin{array}{l}\text { Paration } \\
\text { metílico }\end{array}$ & Organofosforado & $\begin{array}{c}\text { Cinturão Verde, } \\
\text { Talita, São Braz } \\
\text { dos Macacos, } \\
\text { Pindoba }\end{array}$ \\
\hline Roundup & Herbicida & IV & Glifosato & Glicina substituída & Cinturão Verde \\
\hline $\begin{array}{c}\text { Vertimec } 18 \\
\text { CE }\end{array}$ & Inseticida & III & Abamectina & Avermectinas & Cinturão Verde \\
\hline Tamaron & $\begin{array}{r}\text { Inseticida } \\
\text { Acaricida }\end{array}$ & I & Metamidofós & Organofosforado & Talita, Pindoba \\
\hline Glifosato & Herbicida & I & Glifosato & $\begin{array}{c}\text { Gilicina } \\
\text { substituída }\end{array}$ & Iguaíba \\
\hline Barrage & Inseticida & II & Cipermetrina & Piretroide & $\begin{array}{c}\text { São Braz dos } \\
\text { Macacos }\end{array}$ \\
\hline Flytick & $\begin{array}{l}\text { Inseticida } \\
\text { Acaricida }\end{array}$ & II & Cipermetrina & Piretroide & $\begin{array}{c}\text { São Braz dos } \\
\text { Macacos }\end{array}$ \\
\hline Folidol & Inseticida & 1 & $\begin{array}{l}\text { Paration } \\
\text { metílico }\end{array}$ & Organofosforado & Cinturão Verde \\
\hline Herbadox & Herbicida & III & Pendimetalina & Dinitroanilina & Iguaíba \\
\hline
\end{tabular}

Classe toxicológica I = extremamente tóxico; II = altamente tóxico; III = mediamente tóxico; IV = pouco tóxico.

Os inseticidas da classe dos PR (cipermetrina e deltametrina) apresentam toxicidade baixa para os mamíferos, mas podem ser bastante perigosos para outros animais. A cipermetrina, por exemplo, apesar do baixo impacto ambiental e baixa toxicidade para mamíferos mostrou-se muito tóxico para peixes, abelhas, artrópodes aquáticos (camarões e lagostas) e aves (SANTOS, AREAS e REYES, 2007).

O herbicida glifosato também foi considerado de elevado uso pelos agricultores locais. Trata-se de produto muito conhecido, sendo registrado seu uso inclusive para controle de ervas daninhas em pastagens e também em canteiros e jardins nas cidades. É considerado de baixo impacto toxicológico para mamíferos e de muito baixa persistência no ambiente, pois se degrada rapidamente, sobretudo no meio aquático. Contudo, vale mencionar que apesar do composto não permanecer ativo no ambiente por muito tempo, suas formulações são tóxicas para alguns tipos de peixes e outros organismos aquáticos. É interessante observar que (por ser herbicida) o glifosato atua sobre o fitoplâncton, comprometendo seriamente a maioria das cadeias tróficas (FAVERO, SOUZA e MATIAS, 2005).

Além dos inseticidas e herbicidas, os agricultores também fazem uso de adubos químicos e fertilizantes. $\mathrm{O}$ Calbit $\mathrm{C}^{\circledR}$, fertilizante foliar à base de cálcio, é absorvido pelo fruto como complemento para as plantas.

Devido à ineficiência na fiscalização do uso de agrotóxicos no Estado do Maranhão, em 
2003, foi criada a Agência Estadual de Defesa Agropecuária do Maranhão (AGED) que, juntamente com a Agência de Pesquisa Agropecuária e Extensão Rural (AGERP), desenvolve ações de apoio aos agricultores no Estado. Ainda assim, pode-se constatar a deficiência, em muitos locais, de assistência especializada. Faltam informações aos produtores sobre a forma de manuseio, comercialização, preparação e aplicação de agrotóxicos, bem como sobre o uso dos equipamentos de proteção individual. Do total de trabalhadores entrevistados, menos de $20 \%$ utilizava EPI e aqueles que manifestaram essa preocupação usavam somente máscaras inadequadas, luvas e botas. Nenhum dos entrevistados fazia uso do jogo completo de EPI (avental, macacão completo, luvas, botas e máscara química).

Um dos graves problemas observados refere-se ao destino, descarte e reutilização das embalagens. Sabe-se que por força da Lei é obrigatória a devolução pelo usuário das embalagens vazias aos estabelecimentos comerciais, sendo seu descarte final de responsabilidade das empresas produtoras. Além disso, segundo essa mesma legislação, é de responsabilidade dos órgãos de fiscalização a orientação sobre o que fazer com essas embalagens. Contudo, a maioria dos entrevistados (85\%) afirmou desconhecer tal legislação. Alguns autores afirmam que essa é a realidade da maioria das áreas agrícolas brasileiras (DORES e FREIRE, 2001; DOMINGUES et. al., 2004; ARAÚJO et. al., 2001; SOUSA, 2009; PERES e MOREIRA, 2008),

Verificou-se o descarte a céu aberto de diversas embalagens de produtos utilizados por agricultores para o combate de pragas nas localidades de Pindoba e lguaíba. Esse tipo de disposição de lixo tóxico tem sido também prática comum no Brasil (ADISSI e SOBREIRA,1999), trazendo como consequência a poluição do solo e de recursos hídricos (lixiviação dos compostos pelas águas das chuvas), a redução da diversidade biológica desses agroecossistemas, além de intoxicações e riscos para a saúde humana (SOUZA, 2009).

\subsection{PRESENÇA DE RESÍDUOS DE AGROTÓXICOS NAS AMOSTRAS DE ÁGUA E DE SEDIMENTOS}

A Tabela 4 apresenta os resultados das análises de resíduos dos agrotóxicos. Nas amostras de sedimentos, nenhum dos métodos detectou resíduos dos produtos avaliados. Dentre os agrotóxicos encontrados na água, dois pertencem ao grupo dos inseticidas OF, um ao grupo dos inseticidas PR e um ao dos inseticidas OC.

Os ensaios imunoquímicos (ELISA) foram positivos para agrotóxicos inibidores da enzima acetilcolinesterase (AChE) em nível de concentração próximo a $0,2 \mu \mathrm{g} \cdot \mathrm{L}^{-1}$, tanto nas amostras do Açude Talita quanto nas de São Braz dos Macacos. Já a amostra da poça 2 (A4R1 e R2) do pólo Talita apresentou resultado positivo para inibidores da AChE em concentração superior a $0,1 \mu \mathrm{g} \cdot \mathrm{LL}^{-1}$.

Todas as amostras forneceram resultados negativos para os inseticidas PR sintéticos, OC, triazinas e herbicidas acetanilida, quando analisadas por ELISA. Isso pode indicar que os testes imunoquímicos não apresentaram sensibilidade adequada para atingir valores de concentração em níveis de traço. Quando as amostras foram analisadas pelos métodos cromatográficos foi possível identificar e quantificar com exatidão os seguintes princípios ativos: metamidofós e paration metílico (inseticidas OP, inibidores da enzima AChE); permetrina e cipermetrina (inseticidas PR); DDT e Aldrin (inseticidas $\mathrm{OC}$ ).

Os resultados obtidos são alarmantes, pois cerca de $70 \%$ das amostras analisadas apresentaram resíduos do inseticida OF paration metílico. A época de coleta influenciou esse resultado, já que se tratava do período pós-emergente e os inseticidas haviam sido há pouco aplicados (após ou antes da semeadura). Com as primeiras chuvas, a quantidade de resíduos de muitos dos compostos lançados aos agroecossistemas ainda estava bastante elevada. Contudo, o que mais chama a atenção é o fato de ainda ocorrer aplicação de agrotóxicos $\mathrm{OC}$ na região, apesar da proibição do seu uso e banimento dos produtos para comercialização desde o final da década de 80. Esse uso indevido de agrotóxicos OC no Maranhão foi comprovado em outros estudos (ARAÚJO 
et al., 2001; SOUZA, 2009, PINHEIRO, 2009; ASSOCIAÇÃO..., 1993; NUNES, VERBINNEN e NUNES, 2010; PRESOTI, 2009).

\section{TABELA 4 - RESULTADOS DAS ANÁLISES DE ÁGUA DOS PÓLOS AGRÍCOLAS DA ILHA DE SÃO LUÍS}

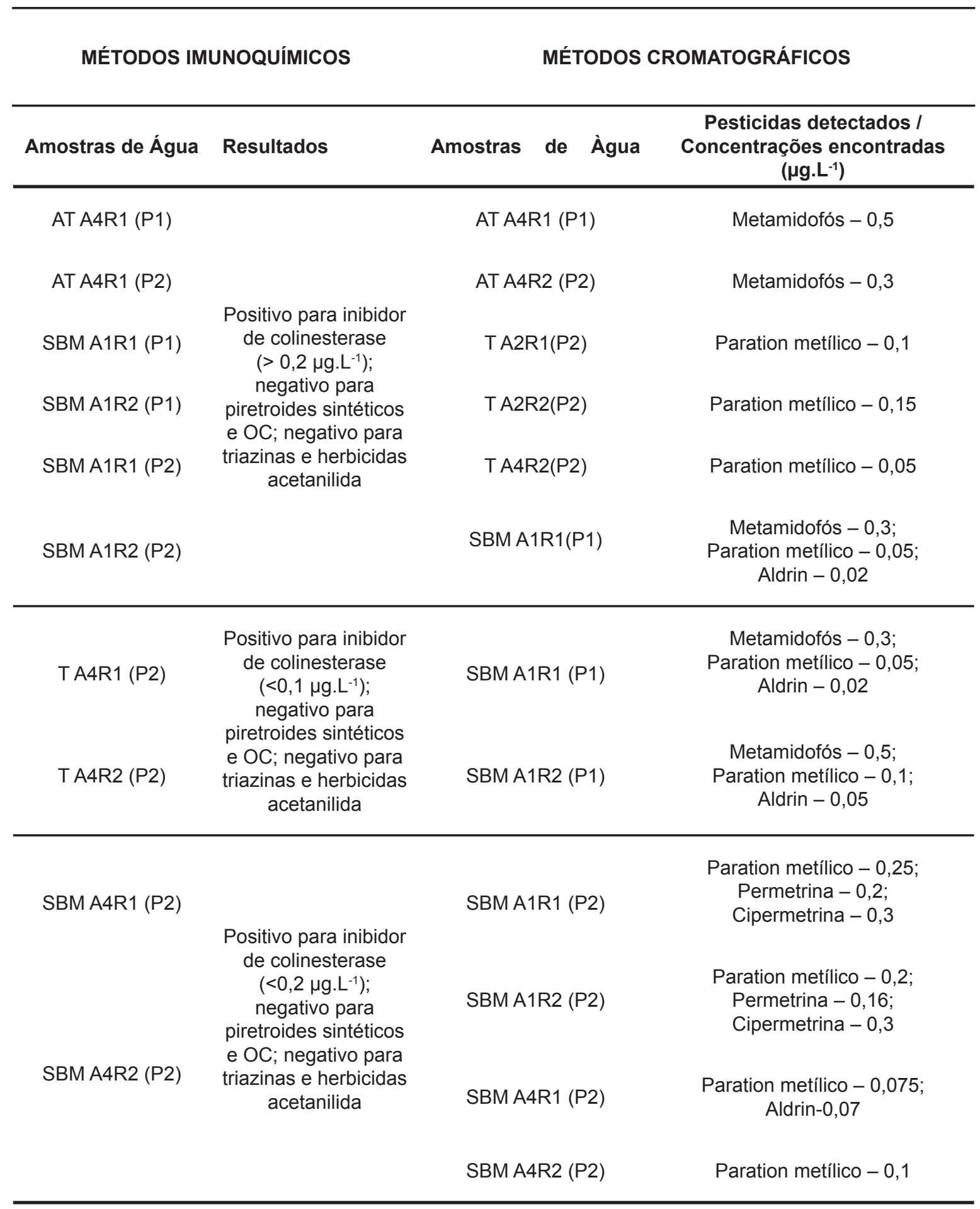

AT = Açude Talita; T = Talita; SBM = São Braz dos Macacos. Amostras (A1, A2, A4); Repetição (R1, R2); Poça (P1, P2); *nd - não detectado; OCS - organoclorados

O princípio ativo Aldrin, inseticida OC, foi encontrado nas concentrações de 0,02 e $0,07 \mu \mathrm{g} \cdot \mathrm{L}^{-1} \mathrm{em}$ amostras de água da localidade de São Braz dos Macacos. Esse inseticida pertence 
à classe toxicológica I (altamente tóxico), tendo como características a elevada persistência no ambiente e tempo de meia vida no solo bastante alta, dependendo das propriedades e textura do solo (MACHADO NETO, 2002). Muitos pesquisadores atentam para o fato de que o composto, extensivamente utilizado no passado em campanhas de combate à malária e também na agricultura, ainda seja detectado em sedimentos, córregos e lagos, aparentando ser também muito comum sua presença em corpos d'água (CARVALHO et al., 1990).

O inseticida OF metamidofós foi encontrado em amostras de água no açude da localidade Talita e em São Braz dos Macacos, nas concentrações 0,3 e 0,5 $\mu \mathrm{g} \cdot \mathrm{L}^{-1}$, respectivamente (Tabela 4). Esses dados são preocupantes, pois o metamidofós apresenta sérios riscos ao ambiente e à saúde humana. A toxicidade desse composto, bastante aplicado no controle de pragas agrícolas, varia entre moderada a alta (dependendo do organismo), sendo considerado muito tóxico para abelhas, pássaros, peixes e crustáceos (LIMA et al., 2001; MACHADO NETO, 2006 ). O metamidófos apresenta tempo de meia vida superior a dois dias no solo e Índice de Guss de 1,56, o que indica improvável lixiviação e baixa probabilidade de ser encontrado em águas superficiais (SANTOS NETO e SIQUEIRA, 2007). No presente estudo, o contaminante foi encontrado em áreas alagadas de baixa profundidade $(30$ a $60 \mathrm{~cm}$ ).

Os resultados obtidos evidenciaram a contaminação de corpos d'água presentes nos pólos agrícolas da llha de São Luis por diversas substâncias tóxicas. Observou-se, durante as visitas aos campos, que a população utiliza alguns desses locais para laser, como fonte de alimentação, para o banho de animais e também para a higienização de instrumentos de trabalho, objetos pessoais e utensílios de cozinha.

A poluição de corpos d'água adjacentes ou em áreas agrícolas tem se mostrado cada vez mais comum, pois as substâncias tóxicas presentes no solo contaminado são introduzidas pela lixiviação nos corpos d'água, podendo interagir no ambiente de diversas maneiras (LEONARDO, 1990; NA et al., 2006). O processo de lixiviação ocorre principalmente devido ao tempo decorrido entre a aplicação do produto e o aparecimento das chuvas. Nesse caso, o produto pode ser perdido para águas da superfície em função da falta de tempo para ser adsorvido pelas partículas coloidais do solo e, portanto, ser arrastado pelas águas da chuva. Esses poluentes podem ter diversos destinos no solo como, por exemplo, serem adsorvidos às suas partículas, sofrerem volatilização, serem absorvidos pelas raízes de plantas e/ou organismos vivos, serem percolados, carreados pelas chuvas, dissolvidos pela água presente no solo, ou mesmo sofrerem decomposição química ou biológica (MACHADO NETO, 1991; NA et al., 2006). Esses fatores e condições ambientais podem de certa forma explicar o fato de não se ter encontrado, nas amostras de sedimento, nenhum resíduo de agrotóxicos.

\section{CONCLUSÃO}

Como o sistema de agricultura familiar predomina na área estudada, os produtores necessitam de assistência técnica e orientações sobre as maneiras corretas de aplicação dos agrotóxicos. Além disso, precisam de informações sobre a toxicologia dos produtos, os cuidados com o ambiente e a biota, a utilização e conservação de equipamentos de proteção individual e o destino final adequado para as embalagens. Os agrotóxicos mais utilizados nos pólos agrícolas avaliados pertencem à classe dos inseticidas OF, seguidos pelos inseticidas PR, destacando-se o uso intensivo do herbicida glifosato de elevado potencial ecotóxico.

Não foram encontrados resíduos de agrotóxicos nas amostras de sedimentos retirados dos corpos d'água, o que sugere a degradação físico-química e microbiológica nesse compartimento ambiental. Além disso, a maior parte dos princípios ativos detectados nas amostras de água apresenta baixo potencial de adsorção no fundo de corpos d'água.

Os inseticidas paration metílico (OF), metamidofós (OF) e cipermetina (PR) foram detectados na maioria das amostras de água. Algumas amostras apresentaram resíduos do inseticida 
organoclorado Aldrin, proibido para uso agrícola no Brasil há quase trinta anos e considerado extremamente tóxico e altamente persistente.

\section{ABSTRACT \\ EVALUATION OF PESTICIDES CONTAMINATION IN WATER BODIES ADJACENT TO AGRICULTURAL AREAS FROM SÃO LUIS ISLAND (MA-BRAZIL)}

In the present study was conducted an investigation on the main pesticides used by agriculturists from the countryside of São Luis Island, Maranhão state (Brazil). The work aimed at examining the levels of contamination of water bodies adjacent to the local agricultural poles. According to the criteria evaluated on this study, the pesticides investigated present risks of contamination to the environment, agriculturists and the general population. In some water samples was also detected the presence of an organochlorine pesticide, which use in agricultural was prohibited in Brazil for more than two decades.

KEY-WORDS: WATER-CONTAMINATION; AGRICULTOR; ENVIRONMENTAL RISK.

\section{REFERÊNCIAS}

1 ADISSI, P.J.; SOBREIRA, A.E.G. Mapeamento de riscos decorrentes do uso de agrotóxicos na horticultura paraibana. João Pessoa, PB: UFPB, 1999. 7 p. (Relatório Técnico).

2 ARAÚJO, S.; LEMOS, R. de; QUEIROZ, M. de; NUNES, G. Uso de inseticidas e organosfororados nos pólos de produção da ilha de São Luís (MA): condições de trabalho e contaminação de hortaliças. Pesticidas: revista de ecotoxicologia e meio ambiente, Curitiba, v.11, p.159-179, 2001.

3 ASSOCIAÇÃO AGROECOLÓGICA TIJUPÁ. As pragas e sua utilização pelos agricultores. São Luís, 1993. 29 p.

4 CALDAS, S.S.; GONÇALVES, F.F.; PRIME, E.G.; PRESTES, O.D.; MARTINS, M.L. Principais técnicas de preparo de amostra para a determinação de resíduos de agrotóxicos em água por cromatografia líquida com detecção por arranjo de diodos e por espectrometria de massas. Química Nova, v.34, p.1604-1617, 2011.

5 CARVALHO, W.A.; MATOS, G.B.; CRUZ, S.L.B.; RODRIGUES, D.S. Intoxicação aguda por aldrin: relação dos níveis séricos com efeitos tóxicos no homem. Revista de Saúde Pública, São Paulo, v.24, p. 39-46, 1990.

6 COUTINHO, C.F.B.; TANIMOTO, S.T.; GALI, A.; GARBELLINI, G.S.; TAKAYAMA, M.; AMARAL, R.B.; MAZO, L.H.; AVACA, L.A.; MACHADO, S.A.S. Pesticidas: mecanismo de ação, degradação e toxidez. Pesticidas: revista de ecotoxicologia e meio ambiente, Curitiba, v.15, p. 65-72, 2005.

7 DOMINGUES, M.R.; BERNARDI, M.R.; ONO, E.Y.S.; ONO, M.A. Agrotóxicos: risco à saúde do trabalhador rural. Revista de Ciências Biológicas e da Saúde, Londrina, v. 25, p. 45-54, 2004.

8 DORES, E.F.G.C.; FREIRE, E.M. Contaminação do ambiente aquático por pesticidas. Estudo de caso: águas usadas para consumo humano em Primavera do Leste, Mato Grosso - análise preliminar. Química Nova, São Paulo, v.24, n.1, p.27-36, jan./fev. 2001.

9 FAVERO, S.; SOUZA, E. M.; MATIAS, R. Ecotoxicidade do paration metílico e glifosato para Poecilia reticulata (PISCES: POECILIIDAE) em laboratório. Ensaios e Ciência, v.9, p.315-324, 2005.

$10 \mathrm{ICH}$. International Conference on Harmonization. Consensus guideline. Validation of analytical procedures: methodology Q2B, step 4. Whashington, DC: Food and Drug Administration, 1996. 186 p.

11 LEONARD, R.A. Movement of pesticides into surface waters. In: CHENG, H.H. (ed.). Pesticides in soil environment: processes, impacts, and modeling. $2^{\text {nd }}$ ed. Madison: Soil Science Society of America, 1990. p.303-349.

12 LIMA, F.J.C.; MARQUES, P.R.B.O.; NUNES, G.S.; TANAKA, S.M.C.N. Inseticida organofosforado metamidofós: aspectos toxicológicos e analíticos. Pesticidas: revista de ecotoxicologia e meio ambiente, Curitiba, v.11, p.17-34, jan./ dez. 2001.

13 MACHADO NETO, J.G. Aldrin. In: FERNÍCOLA, N.; OLIVEIRA, S.S. Poluentes orgânicos persistentes POP. Salvador: Centro de Recursos Ambientais, 2002. p.19-62. (Série Caderno de Referência Ambiental, 13).

14 MACHADO NETO, J.G. Ecotoxicologia de agrotóxicos. Jaboticabal: FCAV - FUNEP, 1991. 49 p.

15 NA, T.; FANG, Z.; ZHANQI, G.; MING, Z.; CHENG, S. The status of pesticide residues in the drinking water sources in Meiliangwan bay, Taihu lake of China. Environmental Monitoring and Assessment, v.123, p.351-370, 2006. 
16 NUNES, G.S. Métodos imunoquímicos para análise de contaminantes ambientais: conceitos, estado da arte e perspectivas. Química Nova, São Paulo, v.28, n.3, p. 462-472, 2005.

17 NUNES, G.R; VERBINNEN, R.T.; NUNES, G.S. Impactos sócioambientais pelos pesticidas empregados na sojicultura sobre a comunidade de Sonhem, região pré-amazônica maranhense. Amazônia, v.6, p.117-132, 2010.

18 PELTZER, P.M.; LAJMANOVICH, R.C.; ATTADEMO, A.M.; BELTZER, A.H. Anuran diversity across agricultural pond in Argentina. Biodiversity and Conservation, v.15, p.3499-3513, 2006.

19 PERES, F.; MOREIRA, J.C. É veneno ou remédio? agrotóxicos, saúde e ambiente. Rio de Janeiro: Ed. Fiocruz, 2003. $384 \mathrm{p}$.

20 PINHEIRO, M.C.D. Avaliação do risco de contaminação por agrotóxicos na comunidade agrícola do município de Centro Novo do Maranhão. 2009. 182 f. Dissertação (Mestrado em Saúde e Ambiente) - Universidade Federal do Maranhão, São Luís, 2009.

21 PRESOTI, A.E.P. Avaliação dos impactos ambientais provenientes da sojicultura na microrregião da Chapadinha, MA. 2009. 117 f. Dissertação (Mestrado Sustentabilidade e Ecossistemas) - Universidade Federal do Maranhão, São Luís, 2009.

22 SANTOS, M.A.T.; AREAS, M.A.; REYES, F.G.R. Piretróides - uma visão geral. Alimentos e Nutrição, Araraquara, v.18, n.3, p. 339-349, jul./set. 2007.

23 SANTOS NETO, A.J.; SIQUEIRA, M.E.P.B. Análise de praguicidas organofosforados em água por extração em fase sólida (spe) utilizando discos c18 e cromatografia em fase gasosa: avaliação da contaminação do reservatório de furnas (MG-Brasil). Química Nova, v.28, n.5, 747-750, 2005.

24 SOUSA, L.T.F. Avaliação do uso de pesticidas nos pólos agrícolas de São Luís, MA. 2009. 69 f. Dissertação (Mestrado em Biodiversidade e Conservação) - Departamento de Biologia, Universidade Federal do Maranhão, São Luís, 2009.

25 US-EPA. Environmental Protection Agency. EPA guidelines: regulatory monitoring and testing water and wastewater sampling. Washington, DC, 2007. 35 p. 